\title{
VAN DER LOO, Hans, VAN REIJEN, Willem, Modernisierung. Projekt und Paradox
}

Gérald Chaix

\section{OpenEdition}

\author{
Journals
}

Édition électronique

URL : http://journals.openedition.org/ifha/2089

DOI : $10.4000 /$ ifha. 2089

ISSN : 2198-8943

Éditeur

IFRA - Institut franco-allemand (sciences historiques et sociales)

Référence électronique

Gérald Chaix, "VAN DER LOO, Hans, VAN REIJEN, Willem, Modernisierung. Projekt und Paradox », Revue de l'IFHA [En ligne], Date de recension, mis en ligne le 01 janvier 1993, consulté le 22 septembre 2020. URL : http://journals.openedition.org/ifha/2089 ; DOI : https://doi.org/10.4000/ifha.2089

Ce document a été généré automatiquement le 22 septembre 2020

(CIFHA 


\title{
VAN DER LOO, Hans, VAN REIJEN, Willem, Modernisierung. Projekt und Paradox
}

\author{
Gérald Chaix
}

1 Traduite en allemand deux ans après sa publication en néerlandais, voici une rapide mise au point sur le concept de "modernisation ». Dans un premier temps, un rapide survol historiographique (Tönnies, Durkheim, Simmel, Weber, Marx, mais - pourquoi? - pas Troeltsch) permet de présenter tout d'abord les quatre variables dont la combinaison constitue la modernisation: la différenciation, la rationalisation, l'individualisation, et la domestication de la nature; puis de rappeler les conditions (notamment psychiques, voir l'oeuvre de $\mathrm{N}$. Elias) qui ont rendu possible le procès de modernisation; et enfin d'évoquer les trois étapes de ce procès: la Renaissance, la Réforme, l'Aufklärung. Dans un deuxième temps, chaque élément est analysé en détail: on peut ainsi suivre et discuter les usages qui en ont été faits au cours du dernier siècle, par les psychanalystes (S. Freud, E. Fromm), les sociologues (K. Marx, N. Luhmann, P. Bourdieu), les philosophes (J. Habermas, M. Foucault) et les anthropologues (M. Mauss, L. Dumont). Utile.

2 Gérald CHAIX 